\title{
The influence of hydroxypropyl- $\beta$-cyclodextrin on the enantioselective hydrolysis of 2-amino phenylpropionitrile catalyzed by recombinant nitrilase
}

Ming-Yang Li and Xue-Dong Wang*

\begin{abstract}
Background: Hydrolysis of 2-amino phenylpropionitrile by nitrilase is a fundamental biochemical reaction that produces chiral phenylalanine. For practical application of this biochemical reaction, researchers have attempted to improve enzyme enantioselectivity and the reaction rate.

Results: The substrate concentration was increased from 100 to $200 \mathrm{mM}$ without substrate inhibition because of the formation of a substrate-hydroxypropyl- $\beta$-cyclodextrin (HP- $\beta-C D)$ complex. Meanwhile, the activity of recombinant nitrilase increased 2.5 times because the addition of HP- $\beta-C D$ solubilized hydrophobic substrates in the aqueous system. Furthermore, the formation of the substrate-HP- $\beta-C D$ inclusion improved the enantioselectivity of the enzymatic reaction toward producing L-phenylalanine (L-Phe). The enantiomeric excess (e.e.) value of L-Phe increased from $65 \%$ to $83 \%$ when the conversion rate reached $50 \%$.

Conclusions: The recombinant nitrilase enantioselectively hydrolyzed 2-amino phenylpropionitrile to produce L-Phe. The addition of HP- $\beta$-CD to the reaction system enhanced the solubility and bioavailability of hydrophobic substrates as well as the enantioselectivity. The results showed that this additive has potential advantages in biochemical reactions of hydrophobic substrates, particularly for enantioselective biosynthesis.
\end{abstract}

Keywords: HP- $\beta-C D$; Recombinant nitrilase; 2-Amino phenylpropionitrile; Enantioselectivity; e.e. value

\section{Introduction}

L-Phenylalanine (L-Phe) is an essential amino acid generally used in food industries, human nutrients, and pharmaceuticals. For example, it is a precursor of some anticancer drugs and the dipeptide sweetener aspartame [1]. In early industrial processes, L-Phe was mainly produced by chemical synthesis. Because of the specific demand for the stereospecific form and the consideration of eco-friendly chemical synthesis, this approach was gradually replaced with bioprocesses, such as microbial fermentation and enzymatic transformation [2].

Nitrilase (EC 3.5.5.1) is an enzyme that converts nitrile to its carboxylic acid or amide [3]. Some important

\footnotetext{
* Correspondence: xdwang@ecust.edu.cn

State Key Laboratory of Bioreactor Engineering, East China University of Science and Technology, 130 Meilong Road, Shanghai 200237, People's Republic of China
}

chiral pharmaceutical intermediates and bulk products, such as acrylic acid [4], (R)-(-)-mandelic acid [5], 3hydroxyvaleric acid [6], and nicotinic acid [7], are produced by nitrile hydrolysis. For example, $(R)-(-)$-mandelic acid, widely used for the production of semisynthetic cephalosporins and anti-obesity agents, is produced by hydrolyzing mandelonitrile $[5,8]$. In addition, other studies focused on strategic optimizations for increasing the reaction rate, reducing substrate inhibition, and improving enzyme enantioselectivity [9-11].

Cyclodextrin (CD) is the generic term for cyclic oligosaccharides that are used frequently as host molecules in supramolecular chemistry. Despite the outside of the CD molecule being hydrophilic, CD contains a hydrophobic cavity that entraps most hydrophobic molecules to form inclusion complexes [12]. Thus, it improves the solubility and bioavailability of hydrophobic compounds. Its

\section{Springer}


use is of interest for reactions in which hydrophobic compounds are to be delivered. In previous reports, CD has been proven to increase the availability of insoluble substrates, reduce substrate inhibition, and enhance the efficiency of catalysis by increasing the reaction rate in other catalytic reactions [13]. It has also been used in an enzymatic enantioselective reaction to increase the enantiomeric excess (e.e.) value of the product [14].

In our previous study, a novel nitrilase from Rhodobacter sp. LHS-305 was cloned and expressed in Escherichia coli [15]. This nitrilase displayed high activity toward both aliphatic and aromatic nitriles, similar to the nitrilase from Rhodococcus rhodochrous ATCC 33278 [16]. It also showed regioselectivity toward dinitriles to produce cyanocarboxylic acids. Because this nitrilase shows properties different from those of typical nitrilases, it potentially has industrial applications in the future.

In this study, the stereoselective hydrolysis of 2-amino phenylpropionitrile by this novel nitrilase was investigated. The influences of CD on this hydrolysis in terms of substrate inhibition and the e.e. value of the product were found to improve the catalytic reaction. The investigations comprehensively increased our knowledge of this unique nitrilase for its application.

\section{Materials and methods Chemicals}

Hydroxypropyl- $\beta$-cyclodextrin (HP- $\beta$-CD) $(\geq 98.5 \%)$ was purchased from Shanghai Lingfeng Chemical Reagent Company (Shanghai, China), biochemical-grade L-Phe from Sigma-Aldrich (St. Louis, MO, USA), and glucose and other chemicals from Sinopharm Chemical Reagent Co., Ltd. (Shanghai, China).

\section{Microorganism and culture media}

Recombinant $E$. coli expressing a novel nitrilase gene from Rhodobacter sphaeroides LHS-305 were used in this study.

Seed medium $(\mathrm{g} / \mathrm{L})$ contained peptone 10 , yeast extract 5 , and $\mathrm{NaCl} 10, \mathrm{pH} 7.0$ to 7.5 .

Fermentation medium $(\mathrm{g} / \mathrm{L})$ contained yeast extract 10, peptone $5, \mathrm{NaCl} 5$, glucose 3, and $\mathrm{MgSO} 4 \cdot 7 \mathrm{H}_{2} \mathrm{O} 3$, $\mathrm{pH} 7.0$ to 7.5 . Media were sterilized for $20 \mathrm{~min}$ at $115^{\circ} \mathrm{C}$.

\section{Growth conditions}

Precultures cultured in the seed medium for 3 to $4 \mathrm{~h}$ at $37^{\circ} \mathrm{C}$ were inoculated into $100 \mathrm{~mL}$ of fermentation medium in a 500-mL Erlenmeyer flask, with the addition of $\alpha$-lactose $(1 \mathrm{~g} / \mathrm{L})$, and cultured on a shaker at $200 \mathrm{rpm}$ and $20^{\circ} \mathrm{C}$ for $12 \mathrm{~h}$.

\section{Preparation of recombinant nitrilase}

The recombinant nitrilase was purified by affinity chromatography as described in our previous report [15].

\section{Preparation of the 2-amino phenylpropionitrile/HP- $\beta$-CD complex}

2-Amino phenylpropionitrile $(73 \mathrm{mg}$ ) was added to $100 \mu \mathrm{L}$ methanol to obtain a $5 \mathrm{M}$ substrate stock solution. The stock solution was added to $50 \mathrm{mM}$ PB solution ( $\mathrm{pH} 7.0$ ) with HP- $\beta-C D$ and stirred for $20 \mathrm{~min}$ at $40^{\circ} \mathrm{C}$. This yielded the 2 -amino phenylpropionitrile/HP$\beta$-CD inclusion complex.

\section{Assay of enzyme activity toward bioconversion of 2-amino phenylpropionitrile}

The catalytic reaction was performed in $1 \mathrm{~mL}$ of sodium phosphate buffer $(50 \mathrm{mM}, \mathrm{pH} 7.0)$ containing the substrate 2-amino phenylpropionitrile $(20 \mathrm{mM}$, final concentration) and nitrilase ( $1 \mathrm{mg} / \mathrm{mL}$, final concentration). Reaction mixtures were incubated at $40^{\circ} \mathrm{C}$ for $10 \mathrm{~min}$, and reactions were quenched by the addition of $10 \%(\mathrm{v} / \mathrm{v})$ $1 \mathrm{~mol} / \mathrm{L} \mathrm{HCl}$. Enzyme activity (U) was defined as the amount of enzyme required for the hydrolysis of $1 \mu \mathrm{mol}$ of the 2-amino phenylpropionitrile substrate to the corresponding acid within $1 \mathrm{~min}$. All experiments were performed in triplicate.

\section{Analysis of L-Phe}

The enantiomeric purity of Phe was determined by reversed-phase HPLC (Agilent, Santa Clara, CA, USA) equipped with a Chirobiotic $\mathrm{T}$ column (Sigma-Aldrich Co.) at a flow rate of $0.5 \mathrm{~mL} / \mathrm{min}$ with a solvent system $(75: 25, v / v)$ of phosphate buffer $(25 \mathrm{mM}$, adjusted to pH 3.5 with $\mathrm{H}_{3} \mathrm{PO}_{4}$ ) and methanol. Peaks were detected using an ultraviolet detector at $210 \mathrm{~nm}$.

\section{Results and discussion}

Effects of HP- $\beta-C D$ addition on the catalytic reaction

SDS-PAGE for the purified nitrilase indicated a single band at $40 \mathrm{kDa}$, naturally corresponding to 14 subunits of identical size [15]. The optimal reaction $\mathrm{pH}$ and temperature of the purified nitrilase were 7.0 and $40^{\circ} \mathrm{C}$, respectively [15]. In the hydrolysis of 2 -amino phenylpropionitrile to L-Phe by the purified nitrilase, the reaction rate was limited by the low solubility of 2 -amino phenylpropionitrile. HP- $\beta$-CD can form a complex with hydrophobic substrates. It may enhance the solubility and bioavailability of such compounds. The diminished transmittances of the cyano group at 2,240 to $2,222 \mathrm{~cm}^{-1}$ by infrared spectrometry indicated that the substrate molecule had been included by HP- $\beta-C D$, as shown in Figure 1 . The effects of $\mathrm{HP}-\beta-\mathrm{CD} /$ substrate molar ratios on enzyme activity were examined, as shown in Figure 2 . The reaction rate was improved significantly 

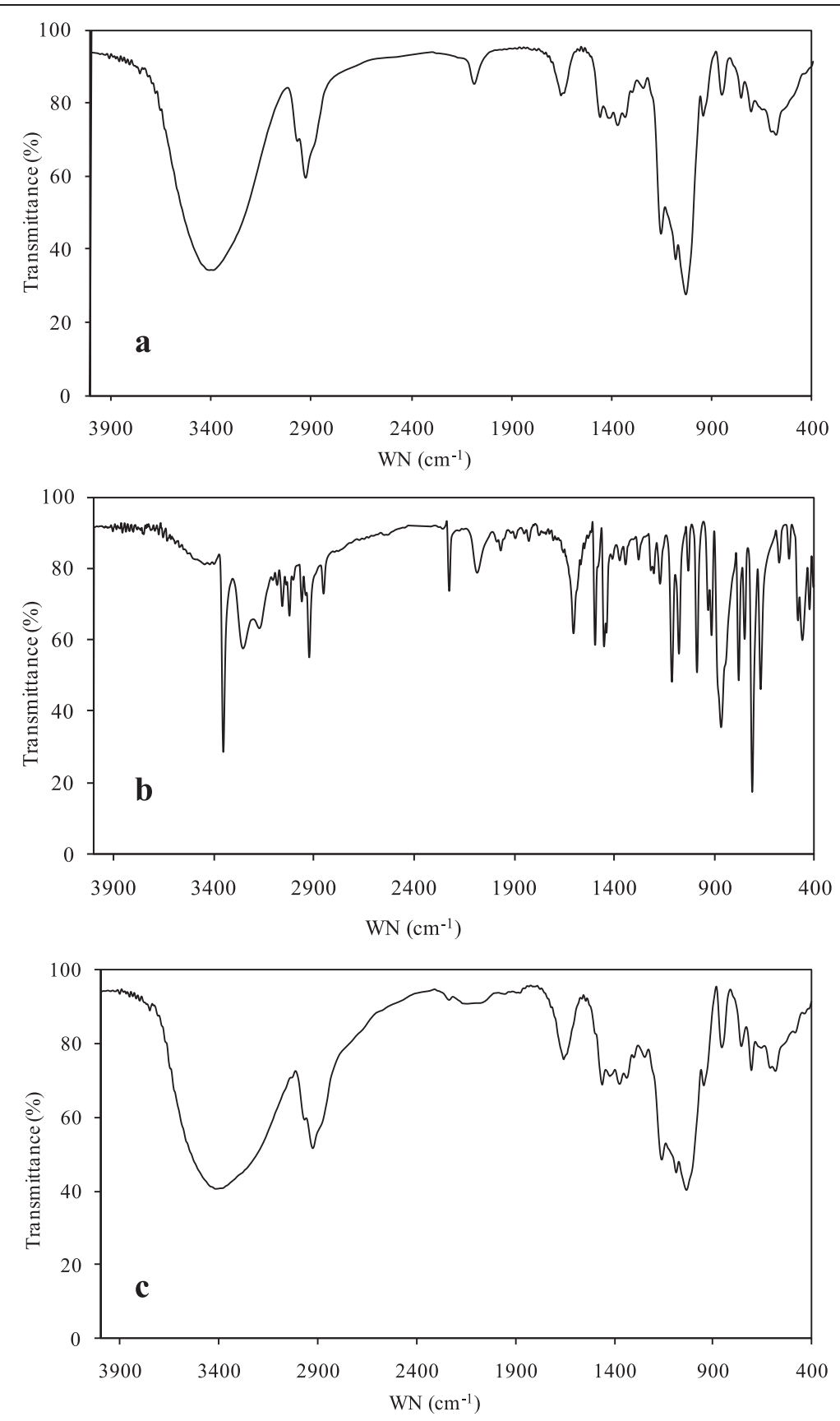

Figure 1 Infrared spectroscopy of the HP- $\beta-C D$, substrate, and HP- $\beta-C D$-substrate inclusion complex. (a) Spectroscopy of HP- $\beta-C D$. (b) Spectroscopy of substrate. (c) Spectroscopy of HP- $\beta$-CD-substrate inclusions.

by the addition of HP- $\beta-C D$, consistent with a previous study in which HP- $\beta-C D$ was used as a solubilizer [17]. The highest relative activity (245\%) was obtained at a ratio of 0.2 . However, the host-guest complex was present in a dynamic equilibrium with free substrates and the inclusion complex. The concentration of free substrates decreased with the increase in $C D$ available for enzymatic attack. Meanwhile, HP- $\beta-C D$ addition also affected the e.e. value of the product. As shown in Figure 2, the e.e. value of the product decreased when the ratio was lower than 0.2. These results showed that the HP- $\beta-C D /$ substrate ratio was a sensitive parameter affecting the reaction rate and the enantiopurity of the product. The optimum HP$\beta$-CD/substrate ratio of 0.2 was selected in subsequent experiments. 


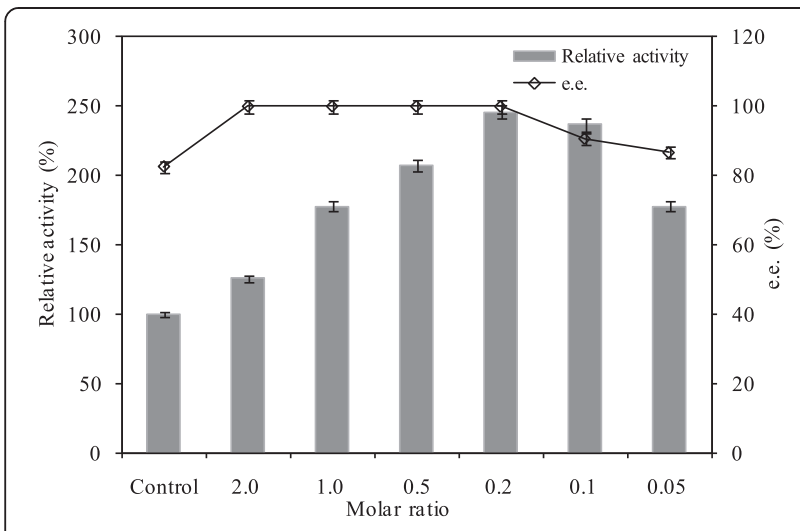

Figure 2 Effect of the HP- $\beta-C D /$ substrate molar ratio on the catalytic reaction. Reactions were carried out in $50 \mathrm{mM}$ sodium phosphate buffer $\left(\mathrm{pH} \mathrm{7.0)}\right.$ at $40^{\circ} \mathrm{C}$ with a substrate concentration of $20 \mathrm{mM}$. HP- $\beta-C D$ was added according to the molar HP- $\beta-C D /$ substrate ratio ( 0.05 to 2.0$)$. The relative activity was tested when the reaction had proceeded for $10 \mathrm{~min}$, and the e.e. value was determined when the conversion rate reached $40 \%$. The actual activity at $100 \%$ was $33.8 \mathrm{U} / \mathrm{mL}$.

\section{Effect of HP- $\beta-C D$ inclusions on substrate inhibition}

The inhibitory effects of substrates with or without HP$\beta-C D$ were investigated, as shown in Figure 3. Significant substrate inhibition was observed, and the initial reaction rate decreased correspondingly as substrate concentration exceeded $100 \mathrm{mM}$ without the addition of HP- $\beta$-CD. It was necessary to eliminate the inhibitory effect of substrate on recombinant nitrilase activity in this biotransformation. Substrate inhibition was reduced by the toluene-water biphasic system or in situ production removal by the addition of resin $[10,18]$. Here, the substrate inhibition was effectively reduced by addition

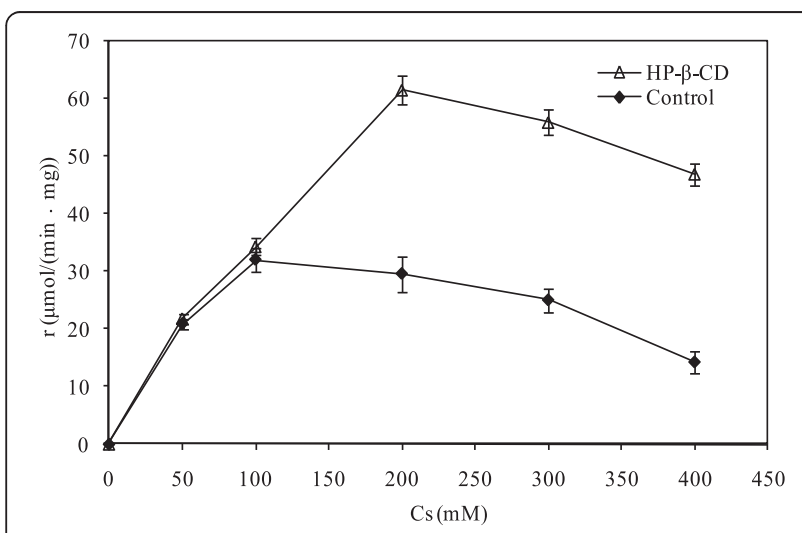

Figure 3 Substrate concentration against initial rate of reaction with and without HP- $\beta-C D$ which was catalyzed by nitrilase.

Reactions were carried out for $10 \mathrm{~min}$ in $50 \mathrm{mM}$ sodium phosphate buffer ( $\mathrm{pH} 7.0$ ) at $40^{\circ} \mathrm{C}$. A constant molar HP- $\beta-\mathrm{CD} /$ substrate ratio of 0.2 was applied.

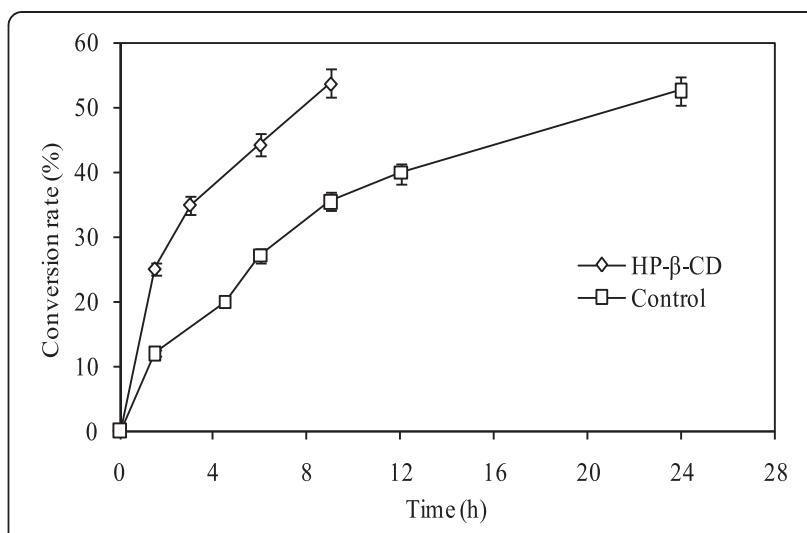

Figure 4 Time course of the biotransformation process. Reactions were carried out in $50 \mathrm{mM}$ sodium phosphate buffer $(\mathrm{pH} 7.0)$ at $40^{\circ} \mathrm{C}$ with a substrate concentration of $200 \mathrm{mM}$. A constant molar HP- $\beta-C D /$ substrate ratio of 0.2 was applied.

of HP- $\beta-C D$ in the reaction system. HP- $\beta-C D$ could form host-guest complexes with hydrophobic substrates. The CD-substrate inclusion complex can function as a reservoir to slowly and continuously release free substrate for the enzymatic reaction. After the substrate was allowed to interact with HP- $\beta-C D$, substrate concentration for the maximum initial rate increased from 100 to $200 \mathrm{mM}$. The maximum initial rate increased from $32 \mu \mathrm{mol} /(\mathrm{min} \cdot \mathrm{mg})$ at a substrate concentration of $100 \mathrm{mM}$ to $62 \mu \mathrm{mol} /(\mathrm{min} \cdot \mathrm{mg})$ at a substrate concentration of $200 \mathrm{mM}$. The reaction time at which the conversion rate reached $50 \%$ was shortened to $9 \mathrm{~h}$ at a substrate concentration of $200 \mathrm{mM}$ in the presence of HP- $\beta-C D$, as shown in Figure 4. The HP- $\beta-C D-$ substrate reaction system greatly increased the bioprocess efficiency.

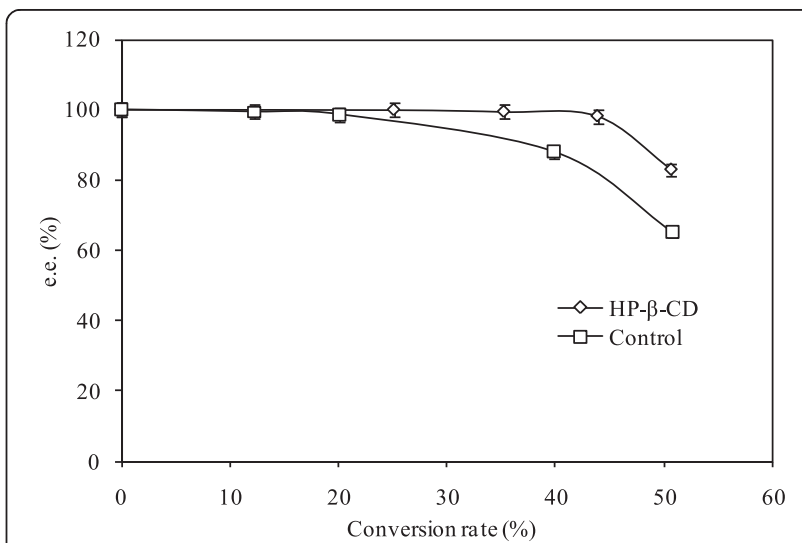

Figure 5 The e.e. value of the product catalyzed by nitrilase with or without HP- $\beta-C D$. Reactions were carried out in $50 \mathrm{mM}$ sodium phosphate buffer $(\mathrm{pH} 7.0)$ at $40^{\circ} \mathrm{C}$ with a substrate concentration of $200 \mathrm{mM}$. A constant molar HP- $\beta-C D /$ substrate ratio of 0.2 was applied. 


\section{Effect of HP- $\beta-C D$ inclusion on the e.e. value of the product}

Enantiomerically pure $\alpha$-hydroxy carboxylic acid or amino acid can be produced by the enzymatic hydrolysis of the cyano group and transesterification or the hydrolysis of an ester group [19]. The recombinant nitrilase enantioselectively hydrolyzed racemic 2 -amino phenylpropionitrile to L-Phe. However, the e.e. value of the product was only $65 \%$ when the conversion rate reached $50 \%$ with a substrate concentration of $200 \mathrm{mM}$. In previous approaches, CDs were used for chiral separation of enantiomer and the enhancement of enantioselectivity in an enzymatic reaction by the formation of CD-substrate inclusion complexes $[14,20]$. When HP- $\beta-C D$ was added to the system to create an inclusion complex, the e.e. value of the product increased to $83 \%$ when the conversion rate reached 50\%, as shown in Figure 5. Although the e.e. value of the product decreased with the increasing conversion rate, an e.e. value of $99 \%$ for the product was obtained when the biotransformation rate reached $40 \%$ after $5 \mathrm{~h}$ of hydrolysis, and the $E$ value was 254 under these optimal reaction conditions. The results showed that the catalytic asymmetric synthesis of L-Phe by the recombinant nitrilase is a typical dynamic kinetic reaction favoring the $\mathrm{D}$ or $\mathrm{L}$ enantiomer. We inferred that the $\mathrm{D}$ type more readily formed inclusion complexes with HP- $\beta$-CD because of the difference in molecular recognition of enantiomer [21]. The D type was contained within the hydrophobic cavity, and the L type was free outside the hydrophobic cavity and was exposed to enzymatic attack. Consequently, the hydrophobic cavity protected and suppressed the hydrolysis of the D enantiomer and led to the enantioselective hydrolysis of an enantiomeric molecule.

\section{Conclusions}

The recombinant nitrilase enantioselectively hydrolyzed 2-amino phenylpropionitrile to produce L-Phe. Using the HP- $\beta$-CD-substrate reaction system, the reaction rate was greatly improved by enhancing the solubility and bioavailability of the hydrophobic substrate. Meanwhile, the e.e. value of the product was also improved significantly because of the formation of inclusion complexes. In this manner, HP- $\beta-C D$ enhanced both the efficiency of the catalytic reaction and the optical purity of the product. The properties of CDs to form inclusion complexes with hydrophobic molecules led to their practical application in a biochemical reaction with a hydrophobic substrate. In particular, they were used to promote enantioselective biosynthesis.

\section{Competing interests}

We hold a Chinese patent relating to the content of the manuscript. The ownership of the patent belongs to East China University of Science and Technology.

\section{Authors' contributions}

MYL carried out the biotransformation process design, product analysis, and data processing. XDW conceived the study, participated in its design and coordination, and helped to draft the manuscript. Both authors read and approved the final manuscript.

\section{Acknowledgements}

We thank Guinan Li and Hualei Wang who provided the fundamental works, such as clone and expression of the novel nitrilase in E. coli.

Received: 30 January 2014 Accepted: 19 May 2014

Published online: 24 July 2014

\section{References}

1. Zhou H, Liao X, Wang T, Du G, Chen J (2010) Enhanced L-phenylalanine biosynthesis by co-expression of pheAfbr and aroFwt. Bioresour Technol 101:4151-4156

2. Liu DX, Fan CS, Tao JH, Liang GX, Gao SE, Wang HJ, Li X, Song DX (2004) Integration of $E$. coli aroG-pheA tandem genes into Corynebacterium glutamicum tyrA locus and its effect on L-phenylalanine biosynthesis. World J Gastroenterol 10:3683-3687

3. Fernandes BCM, Mateo C, Kiziak C, Chmura A, Wacker J, van Rantwijk F, Stolz A, Sheldon RA (2006) Nitrile hydratase activity of a recombinant nitrilase. Adv Synth Catal 348:2597-2603

4. Kamal A, Kumar MS, Kumar CG, Shaik TB (2011) Bioconversion of acrylonitrile to acrylic acid by Rhodococcus ruber strain AKSH-84. J Microbiol Biotechnol 21(1):37-42

5. Banerjee A, Dubey S, Kaul P, Barse B, Piotrowski M, Banerjee UC (2009) Enantioselective nitrilase from Pseudomonas putida: cloning, heterologous expression, and bioreactor studies. Mol Biotechnol 41(1):35-41

6. Wu SJ, Fogiel AJ, Petrillo KL, Hann EC, Mersinger $L$, DiCosimo R, O'Keefe DP, Ben-Bassat A, Payne MS (2007) Protein engineering of Acidovorax facilis 72W nitrilase for bioprocess development. Biotechnol Bioeng 97:689-693

7. Yang CS, Wang XD, Wei DZ (2011) A new nitrilase-producing strain named Rhodobacter sphaeroides LHS-305: biocatalytic characterization and substrate specificity. Appl Biochem Biotechnol 165:1556-1567

8. Zhang ZJ, Xu JH, He YC, Ouyang LM, Liu YY (2013) Cloning and biochemical properties of a highly thermostable and enantioselective nitrilase from Alcaligenes sp. ECU0401 and its potential for (R)-(-)-mandelic acid production. Bioproc Biosyst Eng 34(3):315-322

9. Sosedov O, Matzer K, Bürger S, Kiziak C, Baum S, Altenbuchner J, Chmura A, van Rantwijk F, Stolz A (2009) Construction of recombinant Escherichia coli catalysts which simultaneously express an (S)-oxynitrilase and different nitrilase variants for the synthesis of (S)-mandelic acid and (S)-mandelic amide from benzaldehyde and cyanide. Adv Synth Catal 351:1531-1538

10. Zhang ZJ, Pan J, Liu JF, Xu JH, He YC, Liu YY (2011) Significant enhancement of (R)-mandelic acid production by relieving substrate inhibition of recombinant nitrilase in toluene-water biphasic system. J Biotechnol 152:24-29

11. Qiu J, Su EZ, Wang W, Wei DZ (2014) High yield synthesis of Dphenylglycine and its derivatives by nitrilase mediated dynamic kinetic resolution in aqueous-1-octanol biphasic system. Tetrahedron Lett 55(8):1448-1451

12. Liu L, Guo QX (2004) Use of quantum chemical methods to study cyclodextrin chemistry. J Incl Phenom Macro Chemistry 50(1-2):95-103

13. Yue HY, Yuan QP, Wang WH (2007) Enhancement of L-phenylalanine production by $\beta$-cyclodextrin. J Food Eng 79:878-884

14. Mine $Y$, Zhang L, Fukunaga K, Sugimura $Y$ (2005) Enhancement of enzyme activity and enantioselectivity by cyclopentyl methyl ether in the transesterification catalyzed by Pseudomonas cepacia lipase co-lyophilized with cyclodextrins. Biotechnol Lett 27(6):383-388

15. Wang HL, Li GN, Li MY, Wei DZ, Wang XD (2014) A novel nitrilase from Rhodobacter sphaeroides LHS-305: cloning, heterologous expression and biochemical characterization. World J Microbiol Biotechnol 30:245-252

16. Yeom SJ, Kim HJ, Lee JK, Kim DE, Oh DK (2008) An amino acid at position 142 in nitrilase from Rhodococcus rhodochrous ATCC 33278 determines the substrate specificity for aliphatic and aromatic nitriles. Biochem J 415:401-407

17. Shen Y, Wang M, Zhang L, Ma Y, Ma B, Zheng Y, Liu H, Luo JM (2011) Effects of hydroxypropyl- $\beta$-cyclodextrin on cell growth, activity, and integrity of steroid-transforming Arthrobacter simplex and Mycobacterium sp. Appl Microbiol Biotechnol 90(6):1995-2003 
18. Xue YP, Liu ZQ, Xu M, Wang YJ, Zheng YG, Shen YC (2010) Enhanced biotransformation of (R, S)-mandelonitrile to (R)-(-)-mandelic acid with in situ production removal by addition of resin. Biochem Eng J 53:143-149

19. Gröger H (2001) Enzymatic routes to enantiomerically pure aromatic a-hydroxy carboxylic acids: a further example for the diversity of biocatalysis. Adv Synth Catal 343:547-558

20. Tang K, Miao JB, Zhou T, Liu YB, Song LT (2011) Reaction kinetics in reactive extraction for chiral separation of a-cyclohexyl-mandelic acid enantiomers with hydroxypropyl- $\beta$-cyclodextrin. Chem Eng Sci 66(3):397-404

21. Aree T, Arunchai R, Koonrugsa N (2012) Fluorometric and theoretical studies on inclusion complexes of $\beta$-cyclodextrin and D-, L-phenylalanine. Spectrochim Acta A 96:736-743

doi:10.1186/s40643-014-0004-x

Cite this article as: $L i$ and Wang: The influence of hydroxypropyl- $\beta$ cyclodextrin on the enantioselective hydrolysis of 2-amino phenylpropionitrile catalyzed by recombinant nitrilase. Bioresources and Bioprocessing 2014 1:4.

\section{Submit your manuscript to a SpringerOpen ${ }^{\circ}$ journal and benefit from:}

- Convenient online submission

- Rigorous peer review

- Immediate publication on acceptance

- Open access: articles freely available online

- High visibility within the field

- Retaining the copyright to your article 